Journal of Social Sciences 6 (2): 133-140, 2010

ISSN 1549-3652

(C) 2010 Science Publications

\title{
Mental Health Promotion among Nursing Students
}

\author{
${ }^{1}$ Choochart Deeromram, ${ }^{2}$ Amorn Suwannimitr and ${ }^{1}$ Suwadee Jundeekrayom \\ ${ }^{1}$ Department of Mental Health and Psychiatric Nursing, \\ ${ }^{2}$ Department of Community Health Nursing, \\ Faculty of Nursing, Mahasarakham University, Mahasarakham, Thailand 44150
}

\begin{abstract}
Problem statement: In the literature, there is no consensus over what constitutes an appropriate model for mental health promotion among nursing students in Thailand. Approach: This quasi-experimental research was conducted to evaluate the effects of mental health promotion intervention. Several activities in this intervention were created for promoting sense of coherence which focused on the manipulation of both internal and external factors that effect mental health. Results: The results revealed that prior to the implementation of mental health promotion intervention, both experimental and control groups demonstrated that there were no significant differences on the mean score of all styles of defense mechanisms and sense of coherence either in total or individual dimensions. After intervention were implemented, however, there were significantly differences between groups using mature defense mechanisms $(t=-3.486, \mathrm{p}<0.01)$. The comparison between before and after intervention demonstrated that using mature mechanisms was significantly different $(\mathrm{t}=-2.796, \mathrm{p}<0.01)$. Following implementation, comparison between groups revealed that the sense of coherence scores both in total $(\mathrm{t}=-4.290, \mathrm{p}<0.01)$ and individual dimensions were significantly different in regards to manageability $(t=-3.748, p<0.01)$, comprehensibility $(t=-4.426, p<0.01)$ and meaningfulness $(t=-2.750, p<0.01)$. Comparison prior to and after implementation for the experimental group demonstrated that both scores in total $(t=-6.376, \mathrm{p}<0.01)$ and individual dimensions were significantly different for manageability $(t=-6.031, \mathrm{p}<0.01)$, comprehensibility $(t=-5.696, p<0.01)$ and meaningfulness $(\mathrm{t}=-3.484, \mathrm{p}<0.01)$ whereas for the control group was significantly different only in total $(\mathrm{t}=-2.681, \mathrm{p}<0.01)$ and comprehensibility dimension $(\mathrm{t}=-2.167, \mathrm{p}<0.05)$. Conclusion: These findings reflect the effectiveness of mental health promotion intervention. In order to prepare student nurses most effectively, nursing schools should apply this appropriate interventions with their students.
\end{abstract}

Key words: Mental health promotion, defense mechanisms style, sense of coherence

\section{INTRODUCTION}

Background and significance of the study: In a globalization trend, the world changes every single day, especially in regards to the environment, social functions and cultural aspects. These changes could impact the stress level of people and stimulate their adaptation. Stress is an adaptive phenomenon of human beings which, to the higher degree, contributes to their survival, to an adequate output in their activities and to an effective performance in many phases of life (Pades Jimenez and Homar Amengual, 2006). According to psychoanalytic theory, individual adaptation is the emotional adaptive process and ego defense mechanisms of human beings for dealing with stress (Freud, 1993). Stress, defined by the interaction between the environment and an individual, is experienced when demands from the environment exceed available resources. Overwhelming with stress and anxiety, persons could respond in several manners according to cognitive appraisals and coping competencies (Lazarus and Folkman, 1984).

Situations in the university especially during the academic lives of nursing students, is considered as one of several areas for stress exposure. It exists for students in both the clinical and the academic fields of the studying program (Lazarus and Folkman, 1984). Preparing to become a nurse was found to be significantly emotionally stressful and a possible risk to the well-being of students (Tully, 2004). It involves meeting conflicting demands, feeling over worked, feeling unprepared and seeking respect and support from one's faculty (Magnussen and Amundson, 2003). In a study, financial constraints and academic-related

Corresponding Author: Choochart Deeromram, Department of Mental Health and Psychiatric Nursing, Faculty of Nursing, Mahasarakham University, Mahasarakham, Thailand 44150 


\section{J. Social Sci., 6 (2): 133-140, 2010}

concerns emerged as the most stressful areas for the students (Timmins and Kaliszer, 2002). Nursing student who fulfill their clinical practices are exposed to symptoms specific to nursing in the field of stress (Pades Jimenez and Homar Amengual, 2006). Initial clinical experience for new nursing students can be stressful and intimidating, particularly for young students having no prior healthcare experience (Sprengel and Job, 2004). Additionally, characteristics of nursing profession are significantly and directly related to human health. Therefore, nursing students need to be aware and to be able to utilize the nursing theoretical aspects for high quality clinical practicing. Moreover, nursing shifts and ward rotations, in order to fulfill the patient's needs 24 hours a day also expose nursing students to stress that directly effect their adaptation (Lambert et al., 2007a; 2007b; Xianyu and Lambert, 2006). Therefore if nursing students have an inefficient ability to deal with stress and anxiety in everyday life, they will develop health problems, especially psychological distress quite easily.

In 2006, a participatory action research on the perspectives of defense mechanisms styles and sense of coherence was conducted in order to study mental health in the first year bachelor of nursing science students at the Faculty of Nursing, Mahasarakham University. The findings suggested that nursing students defined mental health as the emotional status, self awareness, concentration and individual adaptive abilities which vary according to situations concerning physical, psychological and environmental. Moreover, they stated that mental health was deeply reciprocal associated with physical health with no other ways of separating each other. They mentioned internal and external factors effected mental health of individuals. Lack of participation in class activities and malpractice of communication were identified as the crucial factors that affected their mental health. Manipulation with personal stress and promoting class participation for solving difficult situations were mentioned as an action plan for promoting mental health which involved self understanding, positive thinking, care and concern, team building, stronger teacher-student relationship and participating of class activity report intervention (Deeromram et al., 2007; 2008). The expected outcomes that focus on health and high competency of nursing professional in the future, therefore, this quasiexperimental study was designed to utilize the action plan from previous study for mental health promotion among nursing students.

Purposes of the study: The quasi-experimental research aimed to study the effect of mental health promotion intervention among nursing students in the Faculty of Nursing, Mahasarakham University.

Literature review: The research was conducted by using the concepts concerning defense mechanisms style and sense of coherence as a conceptual framework. According to the defense mechanisms, Sigmund Freud (1993), the first psychologist who proposed psychoanalytic theory, points out that the theory consists of 3 principle dimensions: Level of mind; structure of mind; and psychosexual development. This theory concerns mental and behavioral disorders of individuals associated with inappropriate ego defense and mental conflict. Or in other words, people who attempt to use coping behaviors when they face difficult situations. Coping behaviors vary with each individual, but all of us use defense mechanisms as one method of coping. Defense mechanisms are automatic psychological processes that mediate individuals' reactions to emotional conflicts and stressors, which often operate without individual awareness. They are not a specific attempt to solve a problem but the use of a mental mechanism to resolve a mental conflict, reduce uncomfortable feelings of anxiety or fear and protect one's self-esteem and sense of security. They protect individuals by allowing them to deny, distort, or restrict full awareness of unpleasant thoughts, feelings and feared impulses (Fortinash and Holoday Worret, 2004; Shives and Isaacs, 2005). The defense mechanisms were evaluated by the Defense Style Questionnaire (DSQ). This questionnaire evaluates twenty defense styles, which are divided into three groups of factors: mature, neurotic and immature. The mature style consists of four defenses (sublimation, humor, anticipation and suppression), as does the neurotic style (undoing, pseudo-altruism, idealization and reaction formation). The remaining, immature style consists of twelve defenses (projection, passiveaggression, acting-out, isolation, devaluation, autistic fantasy, denial, displacement, dissociation, splitting, rationalization and somatization) (Kipper et al., 2007). Individuals with mental and behavioral disorders tend to use maladaptive mechanisms (neurotic and immature defense factor) as coping behaviors (Fortinash and Holoday Worret, 2004; Shives and Isaacs, 2005). Several studies performed in different countries which examined the ego defense mechanisms style found that the results correspond to one another. The endorsement immature defense styles decreases with age (Andrews et al., 1993). Maladaptive defenses were significant positively correlated perceived stress and the using of maladaptive defense mechanisms in older adult was lesser than younger adult (Segal et al., 2007). 


\section{J. Social Sci., 6 (2): 133-140, 2010}

Moreover, the emotional abuse in childhood and perceptions of controlling and non-caring parents had an indirect effect on psychopathology which was mediated by immature defense and low self-esteem (Erikson, 1963; Finzi-Dottan and Karu, 2006).

Sense Of Coherence (SOC) was identified and described by Antonovsky $(1982 ; 1987)$ as the central concept of salutogenic model. This concept reflects an emphasis on health, rather than on illness (pathogenesis), as the phenomenon of interest in a new paradigm guiding research in the field of stress and coping. The hypothesis of this concept was demonstrated that, when confronting stressors, the person with a strong sense of coherence is able to clarify and structure the nature of the stressor, believes that the appropriate resources are available and can be mobilized to deal successfully with the challenge and is motivated to deal with it. High sense of coherence allows the selection of appropriate coping strategies and provides a solid base for maintenance and strengthening of health and well-being. Antonovsky (1982; 1987) defined the sense of coherence as: a global orientation that expresses the extent to which one has a pervasive, enduring though dynamic feeling of confidence that (a) the stimuli deriving from one's internal and external environments in the course of living are structured, predictable and explicable; (b) the resources are available to one to meet the demands posed by these stimuli and (c) these demands are challenges, worthy of investment and engagement. According to this concept, the psychometric instrument Sense of Coherence Rating Scale was developed with three subscales including comprehensibility (the ability to perceive stimuli as ordered, consistent, clear and structured, predictable and explicable), manageability (the ability to perceive that inner and/or outer resources are available, under control and adequate to meet the environmental demands) and meaningfulness (the extend to which the individual finds demands as important, challenging, committed and worthy of investment and engagement) (Bengtsson-Tops and Hansson, 2001). Sense of coherence has been dynamic developed from human life experiences according with the social and cultural context. The sense of coherence level explicit increases in the adolescent period, rather stable around the age of 30 years and can interchange during life time. The consistent and congruence with expectation experiences as well as perceived situations as manageable are considered to encourage sense of coherence level. The studies related to sense of coherence concept have consistently revealed that a high sense of coherence characterizes individuals who cope well with stressful situations whether somatic illness, psychiatric distress, high work-stress or adverse social circumstances. Furthermore, several studies found that the sense of coherence negatively correlated with stress, anxiety, negative life events and depression (Eriksson and Lindstrom, 2005; 2006).

The finding of previous study indicated that sense of coherence was positively correlated with mature defense whereas demonstrated negatively correlation with neurotic and immature defense (Deeromram et al., 2007). Additionally, consensus on what constitutes an appropriate mental health promotion plan was reached after presenting these results to research participants. Manipulation with personal stress and promoting class participation for solving difficult situations were mentioned as an appropriate intervention for promoting mental health. Participants' consensus opinions coincided with the researcher team's and an agreement was reached that any implementation plan should be included by these following activities: self understanding, positive thinking, care and concern, team building, stronger teacher-student relationship and participating of class activity reports (Deeromram et al., 2008).

\section{MATERIALS AND METHODS}

Research design: The quasi-experimental research design was used in this study.

Population and sampling: The target population was second-year-nursing students in the 2007 academic year at the Faculty of Nursing, Mahasarakham University. A total of 107 students participated in the study, they were simple randomly selected and assigned as experimental or control groups. An equal number of students were assigned to each group.

\section{Research instruments:}

Demographic data questionnaire: The demographic data were assessed using Demographic Data Questionnaire which contains demographic characteristics checklists.

Thai Defense Style Questionnaire 40 (DSQ-40): The DSQ-40 was developed by Michael Bond and colleagues (Martini et al., 2004). This questionnaire was translated into Thai by Chaiyot Jittirungson, MD. It consists of 40 items with 9 point semantic differential scale for evaluating 20 defense mechanisms styles. High score in each item reflected the frequency for using defense mechanisms styles which was divided into three groups of factors: Mature (8 items), neurotic (8 items) and immature (24 items). The Alpha 


\section{J. Social Sci., 6 (2): 133-140, 2010}

Cronbach's coefficient of the questionnaires (from the previous study) was 0.88 .

Sense Of Coherence questionnaire (SOC-29): The SOC-29 was developed by Aaron Antonovsky (1982). It was translated into Thai by Professor Dr. Somchit Hanucharurnkul. The questionnaire consists of 29 items (16 positive and 13 negative items) with 7 point semantic differential scale for evaluating sense of coherence level. Reversed score is necessary for the negative items before calculating the total score. Higher total score reflected the stronger sense of coherence. The Alpha Cronbach's coefficient of the questionnaires (from the previous study) was 0.86 .

Mental health promotion plan: The researcher team consists of three nurse lecturers at the Faculty of Nursing, Mahasarakham University. Two of them, teach nursing students in the field of mental health and psychiatric nursing. The remaining one has expertise and teaches in the area of empowerment and community health nursing. Consensus on what constitutes an appropriate mental health promotion plan was reached after consultations with research participants in previous study (Deeromram et al., 2007; 2008). Face validity was done by the expert in the field of mental health and psychiatric nursing. This plan emphasizes on internal and external management factors which involves manipulating personal stress and promoting class participation for solving difficult situations. According to mental health promotion plan developed, the stronger the teacher-student relationship and participation on class activity reports interventions which emerged from previous study were removed. According to the reason for removing these activities, there were implemented as routine activities by the Faculty of Nursing and the Mahasarakham University before conducting this study already. Therefore, the final draft of mental health promotion plan consists of the following interventions:

Self understanding intervention: According to the previous research finding, nursing students mentioned that both internal and external factors affected mental health of individuals. Therefore, the self understanding intervention will be developed based on concepts of self analysis, self awareness and self intervening through growth group to encourage the student for self understanding.

Positive thinking intervention: Regarding the research findings, lack of participation in class activities and malpractice of communication reflected the negative thinking of the nursing students. Based on the concept of Transactional Analysis Theory, positive thinking intervention promotes higher adaptive life position.

Care and concern intervention: Nursing students expressed the lack of care and concern in their class. Based on Transactional Analysis Theory which describes the concept of individual stroking hunger, the care and concern intervention will create supportive atmosphere to encourage self-help activities (friend to friend support and counseling) in class.

Team building intervention: Lack of participation in class activities was identified by nursing students as the crucial factor that affected their mental health. Based on concepts of team building, this intervention promotes teamwork in the classroom.

Protection of human subjects: This study was conducted based on the protection of human rights. Eligible subjects were approached to participate in the study through consent form. The subjects who agreed to participate were assured that data would be kept confidential and reported only as aggregated information. In addition, participants were informed that they could withdraw from the study at any time without any consequences. Regarding the control group, the mental health promotion interventions were implemented again after finishing post intervention data collection. Additionally, the participants were assured that their participation in these activities was voluntarily.

\section{Data collection procedures:}

- The researcher team asked for permission to use the instruments from the Thai researchers who developed the original instruments. Permission to conduct the study was obtained from Dean of the Faculty of Nursing, Mahasarakham University. Baseline data were collected from 107 second-year nursing students in academic year 2007 at the Faculty of Nursing, Mahasarakham University

- From a total of 107 nursing students, they were simple randomly selected for assigning as experimental and control groups which are equal number of sample in each group. In addition, the mental health promotion interventions were implemented with the experimental group. The interventions consisted of four activities and were conducted in two phases during two months

- After the implementation with the experimental group, the post intervention data collection was 


\section{J. Social Sci., 6 (2): 133-140, 2010}

conducted with both groups. Regarding the control group, following post intervention data collection, the mental health promotion interventions were implemented again

Data analysis: Data were analyzed using the SPSS for Windows. Frequencies and parameters were used for data description and the sums of scores for the defense mechanisms styles and sense of coherence were calculated. Independent t-test was used to analyze the differences in scores of the defense mechanisms styles and sense of coherence between experimental and control groups. Paired t-test was also employed to analyze differences within groups.

\section{RESULTS}

The 107 of nursing students, 99 volunteered to participate in this study. The response rate was $92.52 \%$. Forty-six students $(46.46 \%)$ were randomly assigned as the experimental group and $53(53.53 \%)$ as the control group. Concerning the two groups of this study, they were not equal numbers of cases since only volunteered participants were accounted. Fourteen students (14.14\%) of the experimental group dropped out from the study during the second time of interventions. Therefore, the final remaining students of the experimental group were $32(32.32 \%)$.

Defense mechanism style: Prior to the implementation of the mental health promotion intervention, the mean of defense mechanisms style of the experimental group, arranged in order from highest to lowest, were mature $(\bar{X}=6.39, \mathrm{SD}=0.83)$, neurotic $(\bar{X}=5.34, \mathrm{SD}=0.97)$ and immature $(\bar{X}=4.10, \mathrm{SD}=0.83)$. Similarly, for the control group, the mean of defense mechanisms style, in order from highest to lowest, were mature $(\bar{X}=6.24$, $\mathrm{SD}=0.98)$, neurotic $(\overline{\mathrm{X}}=5.40, \mathrm{SD}=0.88)$ and immature $(\bar{X}=4.26, \mathrm{SD}=0.87)$. Comparison between these groups revealed that all styles of defense mechanisms were not significantly different.

Following the implementation of the intervention, the mean of defense mechanisms style of the experimental group, in order from highest to lowest were mature $(\bar{X}=6.89, \mathrm{SD}=1.01)$, neurotic $(\bar{X}=5.23$, $\mathrm{SD}=1.00)$ and immature $(\bar{X}=3.87, \mathrm{SD}=1.03)$. Whilst for the control group, were mature $(\bar{X}=6.16$, $\mathrm{SD}=0.89)$, neurotic $(\overline{\mathrm{X}}=5.35, \mathrm{SD}=0.62)$ and immature $(\bar{X}=4.15, \mathrm{SD}=0.82)$. There were significant differences between the two groups in mature defense mechanisms $(\mathrm{t}=-3.486, \mathrm{p}<0.01)$ whereas the use of neurotic and immature defense mechanisms styles were not significantly different.

The results of the study also showed significant differences in the use of mature defense mechanism styles before and after intervention in the experimental group $(\mathrm{t}=-2.796, \mathrm{p}<0.01)$. However, there were no significant differences in neurotic and immature defense mechanism styles. In regards to the control group, it found that all styles of defense mechanisms were not significantly different.

Sense of coherence: Before implementing mental health promotion intervention, the total mean score on sense of coherence of nursing students in the experimental group was 141.72 (SD = 18.12). The mean scores of the three dimensions: Manageability, comprehensibility and meaningfulness were 49.84 $(\mathrm{SD}=7.39), 46.19(\mathrm{SD}=7.47)$ and $45.69(\mathrm{SD}=5.25)$, respectively. Regarding the control group, the total mean score was $138.64(\mathrm{SD}=13.94)$. The mean score of each dimensions; manageability, comprehensibility and meaningfulness; were $49.47(\mathrm{SD}=6.33), 44.94$ $(\mathrm{SD}=5.57)$ and $44.23(\mathrm{SD}=5.66)$, respectively. Comparison between these groups revealed that both sense of coherence scores in total and each dimension were not significantly different.

After implementing intervention, the total mean score on sense of coherence in the experimental group was 159.16 (SD = 16.38). For each dimension; manageability, comprehensibility and meaningfulness the mean scores were $55.94(\mathrm{SD}=5.71), 46.19$ $(\mathrm{SD}=7.47)$ and $45.69(\mathrm{SD}=5.25)$, respectively. Regarding the control group, the total mean score was $142.83(\mathrm{SD}=17.35)$. The mean score of each dimensions; were $50.87(\mathrm{SD}=6.23), 46.75(\mathrm{SD}=7.77)$ and $45.21(\mathrm{SD}=5.72)$ for manageability, comprehensibility and meaningfulness respectively. Comparison between these groups revealed that both sense of coherence scores in total $(t=-4.290, p<0.01)$ and each dimensions; manageability $(\mathrm{t}=-3.748$, $\mathrm{p}<0.01)$, comprehensibility $(\mathrm{t}=-4.426, \mathrm{p}<0.01)$ and meaningfulness $(\mathrm{t}=-2.750, \mathrm{p}<0.01)$; were significantly different.

According to the comparison score on sense of coherence before and after implementation of intervention, the experimental group demonstrated that both scores in total $(\mathrm{t}=-6.376, \mathrm{p}<0.01)$ and individual dimensions, manageability $(\mathrm{t}=-6.031, \mathrm{p}<0.01)$, comprehensibility $(\mathrm{t}=-5.696, \quad \mathrm{p}<0.01) \quad$ and meaningfulness $(\mathrm{t}=-3.484, \mathrm{p}<0.01)$; were significantly different. Regarding the control group, there were significant differences only in the total score $(t=-2.681$, 


\section{J. Social Sci., 6 (2): 133-140, 2010}

$\mathrm{p}<0.01)$ and comprehensibility dimensions $(\mathrm{t}=-2.167$, $\mathrm{p}<0.05)$.

\section{DISCUSSION}

Before implementing mental health promotion intervention, both experimental and control groups demonstrated that the mean score of all styles of defense mechanisms and sense of coherence, either total or individual dimensions were not significantly different. These findings reflect the general equality in characteristics between the experimental and control sample groups. Furthermore, research results in both groups also revealed that the mean score for mature mechanisms were higher than the others defense mechanisms styles. Moreover, the scores on sense of coherence level were increasing trend. These findings were consistent with the results of the previous study which reflects not only physical and psychological health status but also the quality of characteristics on nursing students (Deeromram et al., 2007). With regards to the results of this study, its congruence with the notion of dynamic sense of coherence level which explicit increases in adolescent period, tends to increase with age over the whole life span, developed from experiences related to socio-cultural of individuals and can change during life time. High sense of coherence level characterizes individuals who cope well with stressful situations whether somatic illness, psychiatric distress, high work-stress or adverse social circumstances whereas low level are positively correlated with stress, anxiety, negative life events and depression (Eriksson and Lindstrom, 2005; 2006).

After implementing mental health promotion intervention, the results illustrated the significant differences between the experimental and control groups using mature defense mechanisms. The experimental group showed higher scores than the control group with significant differences. Similarly, the sense of coherence in the experimental group either total or individual dimensions showed scores higher than the control group with significant differences. Besides, the findings indicated significant differences on the mature defense mechanisms used in the experimental group which before intervention revealed lower scores than after. Moreover, the results showed that the sense of coherence in the experimental group either total or individual dimensions showed to be significantly different with higher scores after implementing intervention. The findings of this research indicated the effectiveness of the activities according to the mental health promotion intervention which was developed by the researcher team and utilized in this study. The results confirmed the outcome of the intervention. The control group showed significant differences in all styles of defense mechanisms. However, the results in this study illustrated that the sense of coherence scores in the control group were significant different in total and comprehensibility dimension. One possible reason might be due to the dynamic sense of coherence level which tends to increase with age over the whole life span, developed from experiences related to the socio-culture of individuals and the interchange during life time (Eriksson and Lindstrom, 2005; 2006).

Regarding the mental health of nursing students in the experimental group, it had clearly progressed after implementing the intervention. This result was confirmed by increased mature defense mechanisms by measuring scores and the sense of coherence level. These findings indicated the effectiveness of the mental health promotion intervention; divided into four activities and separated into two phases; which was explained with the following reasons.

According to the first phase of intervention, the activities of self understanding and positive thinking were implemented. Concerning self understanding activity which has been created for manipulating internal factors of individuals, based on the concepts of self analysis, self awareness and self intervening through the growth of group activities. The objectives of the activities aimed to encourage self understanding. Additionally, positive thinking was consequently implemented to manipulate internal factors in the first phase of intervention. Transactional Analysis Theory (Berne, 1964) was applied to formulate this activity to encourage nursing students to develop and identify themselves as a higher adaptive life position individual (I'm OK, you're OK). One possible explanation was that the thinking process of nursing students in the experimental group might be adapted to the positive aspect after interventions implemented. This advantage was identified by the increasing scores of mature defense mechanisms styles and sense of coherence level. The findings showed similarities with literatures which described that sense of coherence and health status was positively correlated. The high sense of coherence characterizes individuals who cope well with stressful situations. It is strongly related to perceived health, especially mental health. Moreover, sense of coherence seems to be a health promoting resource, which strengthen resilience and develops positive subjective state of health (Eriksson and Lindstrom, 2005; 2006).

With regards to the second phase of intervention, care and concern as well as team building activities 
were implemented. The care and concern activity was created for managing external factors effecting individual health. The theory of Transactional Analysis (Berne, 1964) and Motivation Theory (Maslow, 1970) were utilized to formulate target activity based on concepts of individual stroking hunger. In general, people have motivation to fulfill their needs to be gratified. The belongingness and love needs were identified as one of them. Therefore, these activities may create supportive atmospheres to encourage selfhelp activities (friend to friend supportive and counseling) in class. In addition, team building was consequently implemented to manipulate external factors. According to previous study, lack of participation in class activities was identified as the crucial factor that affected their mental health (Deeromram et al., 2008). Hence, this activity was created based on concepts of effective team building (Daft and Marcic, 2009) to enhance teamwork in a class of nursing students. Possible reasons to explain the advantage of this intervention, team building activities tend to promote sense of belonging and inspire a group of nursing students to be cohesiveness.

\section{CONCLUSION}

With regards to the literature, the sense of coherence is positively correlated with health status. Moreover, it is strongly related to perceived health, especially mental health. Therefore, mental health might be improved through promoting sense of coherence. This research with quasi-experimental method aimed to study the effects of mental health promotion intervention among nursing students. The research findings reflect the effectiveness of mental health promotion intervention. Several activities in this intervention were created focusing on the manipulation of both internal and external factors that effects mental health of individuals. In order to prepare student nurses to fulfill their experiences more effectively, nursing schools should apply these appropriate mental health promotion interventions with their students.

\section{REFERENCES}

Andrews, G., M. Singh and M. Bond, 1993. The defense style questionnaire. J. Nervous Mental Dis., 181: 246-256. PMID: 8473876

Antonovsky, A., 1982. Health, Stress and Coping. 1st Edn., Jossey-Bass, San Francisco, CA., ISBN: 0875894127, pp: 123-197.

Antonovsky, A., 1987. Unraveling the Mystery of Health: How People Manage Stress and Stay Well. 1st Edn., Jossey-Bass, San Francisco, CA., ISBN: 1555420281, pp: 238.
Bengtsson-Tops, A. and L. Hansson, 2001. The validity of Antonovsky's sense of coherence measure in a sample of schizophrenic patients living in community. J. Adv. Nurs., 33: 432-438. PMID: 11251730

Berne, E., 1964. Games People Play: The Psychology of Human Relationships. 1st Edn., Grove Press, New York, ISBN: 0140027688, pp: 13-58.

Daft, R.L. and D.M. Marcic, 2009. Understanding Management. 6th Edn., Mason, USA: SouthWestern Cengage Learning, ISBN: 9780324581782, pp: 518-555.

Deeromram, C., A. Suwannimitr and S. Jundeekrayom, 2007. Defense mechanisms style and sense of coherence of nursing students. J. Facul. Nurs. KKU, 30: 48-56.

Deeromram, C., A. Suwannimitr and S. Jundeekrayom, 2008. Participatory action plan for mental health promotion of nursing students. J. Facul. Nurs. KKU, 31: 9-17.

Erikson, E.H., 1963. Childhood and Society. 2nd Edn., WW Norton and Company, New York, ISBN: 0586083561, pp: 247-274.

Eriksson, M. and B. Lindstrom, 2005. Validity of Antonovsky's sense of coherence scale: A systematic review. J. Epidemiol. Commun. Health, 59: 460-466. PMID: 15911640

Eriksson, M. and B. Lindstrom, 2006. Antonovsky's sense of coherence scale and relation with health: A systematic review. J. Epidemiol. Commun. Health, 60: 376-381. DOI: 10.1136/jech.2006.056028

Finzi-Dottan, R. and T. Karu, 2006. From emotional abuse in childhood to psychopathology adulthood: A path mediated by immature defense mechanisms and self-esteem. J. Nervous Mental Dis., 194: 616621. PMID: 16909071

Fortinash, K.M. and P.A. Holoday Worret, 2004. Psychiatric Mental Health Nursing. 3rd Edn., Mosby Year Book, USA., ISBN: 10: 0323020119, pp: 798.

Freud, A., 1993. The Ego and the Mechanisms of Defense. Karnac Books, London, ISBN: 10: 1855750384, pp: 191.

Kipper, L., C. Blaya, C. Wachleski, M. Dornelles and G.A. Salum et al., 2007. Trauma and defense style as response predictors of pharmacological treatment in panic patients. Eur. Psychiatry, 22: 87-91. PMID: 17188844

Lambert, V.A., C.E. Lambert, M. Petrini, X.M. Li and Y.J. Zhang, 2007a. Predictors of physical and mental health in hospital nurses within the People's Republic of China. Int. Nurs. Rev., 54: 85-91. PMID: 173059962 
Lambert, V.A., C.E. Lambert, M. Petrini, X.M. Li and Y.J. Zhang, 2007b. Workplace personal factors associated with physical and mental health in hospital nurses in China. Nurs. Health Sci., 9: 120-126. DOI: 10.1111/j.1442-2018.2007.00316.x

Lazarus, R.S. and S. Folkman, 1984. Stress, Appraisal and Coping. 1st Edn., Springer Publishing, New York, ISBN: 10: 0826141900, pp: 445.

Magnussen, L. and M.J. Amundson, 2003. Undergraduate nursing student experience. Nurs. Health Sci., 5: 261-267. PMID: 14622377

Martini, P.S., P. Roma, S. Sarti, V. Lingiardi and M. Bond, 2004. Italian version of the defense style questionnaire. Compr. Psychiatry, 40: 333-338. PMID: 15526260

Maslow, A.H., 1970. Motivation and Personality. 2nd Edn., Harper and Row, Publishers, USA., pp: 35-58.

Pades Jiménez, A. and C. Homar Amengual, 2006. Student stress in clinical practice for nurses. Revista de Enfermeria Barcelona Spain, 29: 19-24. PMID: 17061469

Segal, D.L., F.L. Coolidge and H. Misuno, 2007. Defense mechanism differences between younger and older adults: a cross-sectional investigation. Aging Mental Health, 11: 415-422. PMID: 17612805
Shives, L.R. and A. Isaacs, 2005. Basic Concept of Psychiatric-Mental Health Nursing. 6th Edn., Lippincott Williams and Wilkins, Philadelphia, ISBN: 0781728134, pp: 9-12.

Sprengel, A.D. and L. Job, 2004. Reducing student anxiety by using clinical peer mentoring with beginning nursing students. Nurs. Educ., 29: 246-250. PMID: 15586121

Timmins, F. and M. Kaliszer, 2002. Aspects of nurse education programmes that frequently cause stress to nursing students-fact-finding sample survey. Nurse Educ. Today, 22: 203-211. PMID: 12027601

Tully, A., 2004. Stress, sources of stress ways of coping among psychiatric nursing students. J. Psychiatr. Mental Health Nurs., 11: 43-47. PMID: 14723638

Xianyu, Y. and V.A. Lambert, 2006. Investigation of the relationships among workplace stressors, ways of coping and the mental health of Chinese head nurses. Nurs. Health Sci., 8: 147-155. PMID: 16911174 